Dear author,

Please note that changes made in the online proofing system will be added to the article before publication but are not reflected in this PDF.

We also ask that this file not be used for submitting corrections. 


\title{
In the name of truth: People's reactions to ingroup and outgroup members who self-disclose a severe error
}

\author{
Q1 Marika Rullo ${ }^{\mathrm{a}, *}$, Sharon Monaco ${ }^{\mathrm{b}}$, Federico Giannini ${ }^{\mathrm{b}}$, Stefano Livi ${ }^{\mathrm{b}}$, \\ Fabio Presaghi ${ }^{\mathrm{b}}$ \\ Q2 a University of Kent, School of Psychology, United Kingdom \\ b University of Rome "Sapienza”, Department of Social Psychology, Italy
}

\section{A R T I C L E I N F O}

\section{Article history:}

Received 24 April 2018

Received in revised form 12 July 2018

Accepted 13 July 2018

Available online $\mathrm{xxx}$

\section{Keywords:}

Self-disclosure

Morality

Moral judgments

Whistleblowers

Confession

\begin{abstract}
A B S T R A C T
Usually people consider morality traits to be highly valuable, both in themselves and in others. Moreover, they tend to select moral groups and are often motivated to protect the positive identity of their groups by derogating immoral ingroup members. However, sometimes even moral ingroup members could represent a threat to the group and therefore be negatively evaluated, such as in the case of people who report another person's wrongdoing (whistleblowing). To date an investigation of people's judgments of someone who selfdisclose his/her own wrongdoing is still missing. Our study aims to investigate how group members react to an ingroup and an outgroup member who confessed to having committed a severe wrongdoing. Results of a study conducted by using a real episode concerning a surgeon who confessed a fatal error, confirm our expectation; even if medical students appreciated the confession of the surgeon, they are less positive in evaluating his behavior compared to other students.
\end{abstract}

(c) 2018 Published by Elsevier Inc. on behalf of Western Social Science Association.
Usually people consider morality traits like sincerity and honesty to be highly valuable, and this is so both when evaluating themselves and when doing so with others (Cohen \& Sherman, 2014; Haidt \& Joseph, 2007; Schwartz, 2015). Moreover, they tend to select moral groups and are happy if their groups show moral superiority over other groups (Branscombe, Ellemers, Spears, \& Doosje, 1999; Ellemers, Pagliaro, Barreto, \& Leach, 2008), primarily because an important part of people's self-concept is derived from the group they belong to (Brewer \& Hewstone, 2004; Hewstone, Rubin, \& Willis, 2002; Presaghi \& Rullo, 2018; Tajfel \& Turner, 1979). For the same reason, they are often motivated to protect the positive identity of their

\footnotetext{
* Corresponding author.

E-mail addresses: M.Rullo@kent.ac.uk, marika.rullo@uniroma1.it (M. Rullo).
}

group, upgrading moral group members over moral outgroup members and, additionally, derogating immoral and negative ingroup members (more so than outgroup members) that put the group's positive identity at stake (a phenomenon called black sheep effect, Abrams, Travaglino, Marques, Pinto, \& Levine, 2018; Marques \& Paez, 1994; Marques, Paez, \& Abrams, 1998; Marques, Abrams, \& Serôdio, 2001; Rullo, Presaghi, Livi, Mazzuca, \& Dessi, 2017; Sammut, Bezzina, \& Sartawi, 2015).

According to Subjective Group Dynamics Theory (SGDT, Abrams, Marques, Bown, \& Henson, 2000), people are generally motivated to sustain the validity of ingroup norms such as honesty and morality. Ingroup members who engage in deviant acts threaten such validity and therefore are criticised and derogated, and more so than comparable members of external groups, as underlined by the black sheep effect. Another explanation for the emergence of the black sheep effect concerns differences in the elaboration 
of information regarding deviant members of ingroups and outgroups (Reese, Steffens, \& Jonas, 2013). According to Reese et al. (2013), judgments of ingroup deviant members requires systematic processing while outgroup deviant behaviour is evaluated using heuristic processing (ELM, Petty \& Cacioppo, 1986) and this difference may account for the differences in judgment (more or less extreme).

The idea that people deploy more cognitive resources managing information about deviant members (Coull, Yzerbyt, Castano, Paladino, \& Leemans, 2001) underlines the importance of group membership for the self-concept, especially when important parts of one's self-identity are at stake. Moreover, researchers have ascertained that, although both immoral ingroup and outgroup members are avoided and kept at a distance (Brambilla, Sacchi, Pagliaro, \& Ellemers, 2013; Iachini, Pagliaro, \& Ruggiero, 2015; Pagliaro, Brambilla, Sacchi, D’Angelo, \& Ellemers, 2013), individuals perceive them quite differently: an immoral ingroup member is considered a threat to the group image, while an immoral outgroup member is considered a threat to the group safety (Brambilla et al., 2013 Ellemers et al., 2013).

However, sometimes even moral members could be perceived as threat to the group image and therefore be negatively evaluated. For instance, the act of reporting to a third party another person's unethical behaviour, a wrongdoing or a severe mistake that could lead to severe consequences, also called whistleblowing, is often considered a grave betrayal (Bocchiaro, Zimbardo, \& Van Lange, 2012; Dungan, Waytz, \& Young, 2015; Kumagai, 2004; Trevino \& Victor, 1992; Waytz, Dungan, \& Young, 2013). This is due to the fact that whistleblowing, even if it is beneficial for the group in terms of cooperation (Feinberg, Willer, \& Schultz, 2014) and preservation of fairness, is considered a disloyal act and may be regarded as a threat to the harmony between group members. Given that whistleblowing concerns the reporting of another person's negative behaviour, it appears understandable that this behaviour may be perceived as disloyal. How though do group members react to someone who selfdiscloses a negative behaviour such as a grave mistake? One might presuppose that, because the confession concerns that person him/herself and not another group member, people would not consider the confession to be a betrayal. However, although various studies have examined whistleblowing and a number of experimental studies have clarified the complex nature of this phenomenon (Dungan et al., 2015), a study of how people judge someone who self-discloses a wrongdoing has yet to be conducted.

Our study aims to investigate this topic, starting from the idea that people may evaluate a fellow group member who self-discloses a severe mistake less positively compared to an outgroup member making the same revelation. This hypothesis is based on the fact that admitting to having committed a mistake, though it is an act that requires honesty and sincerity, represents a threat to the group members. Possible reasons are: (1) it could represent a moral standard that is too hard to follow by other group members and (2) it could display a weakness of the group that jeopardises its positive social identity.
Based on the predictive value of the black sheep effect, we assume that a deviant ingroup member who threatens the participants' social identity will receive harsher evaluation, even if the deviant member is a moral deviant (rather than the immoral deviant presupposed in the classic black sheep effect).

In our study we have used the confession of a severe mistake that, though not an immoral act (because it was involuntary), could nonetheless represent a threat to the group's identity; for this reason self-disclosure of the mistake may be not highly valued by other group members who would prefer to suppress the mistake in order to preserve the positive group image. Research on the black sheep effect has shown that in fact a poor performance by an ingroup member is usually devalued more than similar poor performance by an outgroup member, especially when the social identity of the group is put at the stake. According to the same mechanism, a severe mistake committed by an ingroup member may also produce a threat to the group, especially when it is strongly related to the group's identity definition.

In order to test our prediction, we conducted a study of a real episode reported in an Italian newspaper, ${ }^{1}$ and asked participants to evaluate a surgeon who admitted to having killed a patient by committing a fatal error during surgery. For physicians in general, and for surgeons specifically, committing an error can have important consequences both for their own career and for their patients; thus we believed that this type of mistake (resulting in the death of a patient during surgery), even if involuntary and accidental, could be perceived by other ingroup members (i.e. other doctors) as a severe threat to the overall group. Thus, a surgeon who self-discloses having committed a fatal error during surgery could be devalued, in spite of his honesty, by ingroup members but valued by outgroups.

\section{Method}

\subsection{Participants}

A final sample of 149 Italian students (111 female, Q5 mean age $\mathrm{M}=22.8, \mathrm{SD}=3.56$ ) took part in this research by completing an online survey. We selected both medical students $(N=62)$ and students on other degree courses $(N=87$ : psychology, sociology and business students), in order to test our hypothesis that medical students (ingroup) would be less positive in evaluating the surgeon who confessed to having committed a fatal error than non-medical students (outgroup). We assumed that medical students might perceive the surgeon as an ingroup member by identify themselves within the overall group of physicians in which surgeons are included considering also that all surgeons are physicians and have been medical students.

\footnotetext{
1 Proietti, M. 2017. Palermo, paziente muore nell'intervento. Il medico: "È colpa mia". Retrieved 27 May. Available online: http://www.ilgiornale.it/news/cronache/palermo-paziente-muorenellintervento-medico-colpa-mia-1402643.html.
} 


\subsection{Materials and procedure}

The participants were contacted via email and invited to complete an online survey in which the news report from an Italian newspaper ${ }^{1}$ was included. The instructions asked participants to read the article, about an Italian surgeon who admitted to having committed a fatal error during the surgery, which resulted in the death of the patient. The patient was a 38 years old man who was subjected to a routine intervention, which lasted six hours because of a surgeon's mistake. The doctor was performing the laparoscopy operation when, mistakenly, he severed the abdominal aorta and perforated the patient's intestine. However, after the intervention, the surgeon confessed to have made a serious mistake and immediately admitted his responsibilities.

After reading the article, participants were invited to respond to four items concerning the suitability of the target behaviour: "The surgeon was right to tell the truth", "The surgeon should have avoided telling the truth (reverse item)", "Telling the truth is the best thing he could do in that situation" and "The surgeon shouldn't tell the truth in order to avoid damaging the image of the surgeons" (alpha .80), and 3 items concerning how much they appreciated the surgeon's behaviour (liking): "I appreciated the surgeon's honesty", "I'm glad to hear about people who aren't afraid to be honest" and "I find the surgeon's honesty inappropriate (reverse item)" (alpha .75). Agreement with the items was assessed using a 5-point Likert scale ranging from 1 ("not at all") to 5 ("completely"). Finally, participants reported their age, gender, nationality and degree class. The presented survey did not include any other measures except the reported ones.

\section{Results}

In order to account for potential participant gender effects, including interactive effects, on our dependent variables, we performed two 2 (ingroup vs. outgroup) $\times 2$ (participant gender) between-subjects ANOVAs. Results showed hat gender had any significant impact both on suitability $(\mathrm{p}=.854)$ and on liking of target's behaviour $(p=.486)$. Also the interaction effect were not significant both for suitability $(\mathrm{p}=.121)$ than for liking index $(\mathrm{p}=.752)$.

In order to verify whether group membership (ingroup vs outgroup) affects judgments about the suitability of the self-disclosing behaviour, we performed a one-way ANOVA. Preliminary homogeneity of variance test was significant (Levene test $F(1,147)=7.83, p=.006$ ) so we considered robust version of F-test for the ANOVA that revealed a significant difference between groups (robust Welch $\mathrm{F}(1,102.1)=10.13, \mathrm{p}=.002, \eta 2=0.072)$, thus medical students seem to evaluate less positive the surgeon's behaviour than other students (Mingroup $=3.46, \mathrm{SD}=.82$ and Moutgroup=3.85, $\mathrm{SD}=.57$ ).

Another ANOVA, performed by using the liking index as dependent variable. Also in this case the homogeneity test was significant (Levene test $F(1,147)=4.72, \mathrm{p}=0.031$ ) so again we considered the robust version of $\mathrm{F}$ test. Results show a similar pattern of results (robust Welch $\mathrm{F}(1$, $98.72)=9.85, \mathrm{p}=.002, \eta 2=0.071)$ : medical students show less appreciation of the surgeon compare to other students (Mingroup = 3.85, SD=.74 and Moutgroup=4.19, SD=.49).

Finally, a further ANOVA performed by using only the fourth item of the suitability scale concerning the damage to the reputation of the overall group of surgeons, revealed that medical students were more severe in evaluating the surgeon's self disclosure (robust Welch F (1, $90.63)=3.75, \mathrm{p}=.056, \eta 2=0.051)$ compare to outgroup participants $($ Mingroup $=2.00, S D=1.08 ;$ Moutgroup $=1.70$, $\mathrm{SD}=0.75)$.

\section{Discussion and conclusion}

In the present study we investigate how differently people judge an ingroup and an outgroup member who self-discloses a fatal error. We hypothesised that people would appreciate the self-disclosure of the outgroup member more than that of the ingroup member. The results confirm our expectation, showing that, compared to their non-medical counterparts, medical students are less positive in evaluating and appreciating the admission of a surgeon to committing a fatal error during surgery. Although we did not test the theoretical explanation of this finding experimentally, primary evidence for the black sheep effect (Abrams et al., 2001; Marques \& Paez, 1994; Rullo, Livi, Pantaleo, \& Viola, 2017) suggests that people tend to derogate ingroup members who threaten the group's positive identity. Consequently, our interpretation of the present findings is that, even if his action was moral, the surgeon who self-disclosed a fatal error is perceived as threatening the overall positive identity of physicians and, for this reason, his behaviour is less valued by ingroup members than by outgroup members. The perception of threat is the key explanatory factor in our findings: the reaction to immoral - and in our case moral - ingroup members is motivated by the threats to self and group image that they may present. Given that a moral behaviour such as the self-disclosure of a fatal error could represent a threat to the self (i.e. by setting a standard of moral behaviour that is too stringent for other group members to emulate) and to the overall group image (i.e. by showing a weakness in the professional category), the evaluation of such honesty is negatively inflected.

We are aware that the research presented has limitations (e.g. small sample size, generalizability) and that other studies are needed in order to test the role of threats to the group in determining judgments of a positive behaviour such as self-disclosure of serious error, but we believe that it should serve as a starting point for further analyses of reactions to general moral deviance in groups. In particular, future studies should take into consideration the role of other important moderators of the discussed effect, e.g. self-disclosure of an immoral or negative act rather than an accidental mistake. If our theoretical predictions about threats to group identity are congruent with the psychological mechanisms behind ingroup reactions to self-disclosure, a harsher devaluation of an ingroup self-discloser compared to an outgroup one would again be expected. Another important issue that future research could overcome concerns the assumption that medical students have perceived the surgeon as an ingroup member.
22 
Even thought we assumed that medical students identify themselves within the overall group of physician in which surgeons are included, we have not a direct evidence of the degree of identification of medical students with the surgeon. Further research should address this issue by assessing directly the identification of people within the target group and by using an experimental group's manipulation. In addition, future research could investigate ingroup reactions to self-disclosure in relation to the group's cultural context; some groups may be more careful to protect their public image than others, which would result in different evaluations of honest ingroup disclosures that threat the positivity of that image. Finally, future studies could examine whether the central and peripheral information processing routes (Petty \& Cacioppo, 1986; Reese et al., 2013) could account for the differences in the evaluations of ingroup or outgroup moral people who threat the group's positive identity.

In conclusion, the findings of this study underline how to studying real events and real contexts could represents a valid strategy to test theories of social psychology and their predictive power.

\section{References}

Abrams, D., Marques, J. M., Bown, N., \& Henson, M. (2000). Pronorm and anti-norm deviance within and between groups. Journal of Personality and Social Psychology, 78(5), 906. http://dx.doi.org/10.1037/0022-3514.78.5.906

Abrams, D., Travaglino, G. A., Marques, J. M., Pinto, I., \& Levine, J. M. (2018) Deviance credit: Tolerance of deviant ingroup leaders is mediated by their accrual of prototypicality and conferral of their right to be supported. Journal of Social Issues, 74(1), 36-55.

Bocchiaro, P., Zimbardo, P. G., \& Van Lange, P. A. (2012). To defy or not to defy: An experimental study of the dynamics of disobedience and whistle-blowing. Social Influence, 7(1), 35-50. http://dx.doi.org/10.1080/15534510.2011.648421

Brambilla, M., Sacchi, S., Pagliaro, S., \& Ellemers, N. (2013). Morality and intergroup relations: Threats to safety and group image predict the desire to interact with outgroup and ingroup members. Journal of Experimental Social Psychology, 49(5), 811-821. http://dx.doi.org/10.1016/j.jesp.2013.04.005

Branscombe, N. R., Ellemers, N., Spears, R., \& Doosje, B. (1999). The context and content of social identity threat. In Social identity: Context, commitment, content. pp. 35-58.

Brewer, M. B., \& Hewstone, M. E. (2004). Self and social identity. Blackwell Publishing.

Cohen, G. L., \& Sherman, D. K. (2014). The psychology of change: Self-affirmation and social psychological intervention. Annual Review of Psychology, 65 http://dx.doi.org/10.1146/ annurev-psych-010213-115137

Coull, A., Yzerbyt, V. Y., Castano, E., Paladino, M. P., \& Leemans, V. (2001). Protecting the ingroup: Motivated allocation of cognitive resources in the presence of threatening ingroup members. Group Processes and Intergroup Relations, 4(4), 327-339.

Dungan, J., Waytz, A., \& Young, L. (2015). The psychology of whistleblowing. Current Opinion in Psychology, 6, 129-133. http://dx.doi.org/ 10.1016/j.copsyc.2015.07.005

Ellemers, N., Pagliaro, S., Barreto, M., \& Leach, C. W. (2008). Is it better to be moral than smart? The effects of morality and competence norms on the decision to work at group status improvement. Journal of Personality and Social Psychology, 95(6), 1397.
Feinberg, M., Willer, R., \& Schultz, M. (2014). Gossip and ostracism promote cooperation in groups. Psychological Science, 25(3), 656-664. http://dx.doi.org/10.1177/0956797613510184

Haidt, J., \& Joseph, C. (2007). The moral mind: How five sets of innate intuitions guide the development of many culture-specific virtues, and perhaps even modules. The Innate Mind, 3, 367-391.

Hewstone, M., Rubin, M., \& Willis, H. (2002). Intergroup bias. Annual Review of Psychology, 53(1), 575-604.

Iachini, T., Pagliaro, S., \& Ruggiero, G. (2015). Near or far? It depends on my impression: Moral information and spatial behavior in virtual interactions. Acta Psychologica, 161, 131-136. http://dx.doi.org/10.1016/j.actpsy.2015.09.003

Kumagai, J. (2004). The whistle-blower's dilemma. IEEE Spectrum, 41(4), 53-55.

Marques, J. M., \& Paez, D. (1994). The 'black sheep effect': Social categorization, rejection of ingroup deviates, and perception of group variability. European Review of Social Psychology, 5(1), 37-68 http://dx.doi.org/10.1080/14792779543000011

Marques, J. M., Paez, D., \& Abrams, D. (1998). Social identity and intragroup differentiation: The "black sheep effect" as a function of subjective social control. In Current perspectives on social identity and social categorization. pp. 124-142. New York: Sage. http://dx.doi.org/10.4135/9781446279205.n9

Marques, J., Abrams, D., \& Serôdio, R. G. (2001). Being better by being right: Subjective group dynamics and derogation of in-group deviants when generic norms are undermined. Journal of Personality and Social Psychology, 81(3), 436.

Pagliaro, S., Brambilla, M., Sacchi, S., D’Angelo, M., \& Ellemers, N. (2013). Initial impressions determine behaviours: Morality predicts the willingness to help newcomers. Journal of Business Ethics, 117(1), 37-44. http://dx.doi.org/10.1007/s10551-012-1508-y

Petty, R. E., \& Cacioppo, J. T. (1986). Message elaboration versus peripheral cues. In Communication and persuasion. pp. 141-172. New York, NY: Springer.

Presaghi, F., \& Rullo, M. (2018). Is social categorization spatially organized in a "mental line"? Empirical evidences for spatial bias in intergroup differentiation. Frontiers in Psychology, 9, 152. http://dx.doi.org/ 10.3389/fpsyg.2018.00152

Reese, G., Steffens, M. C., \& Jonas, K. J. (2013). When black sheep make us think: Information processing and devaluation of in- and outgroup norm deviants. Social Cognition, 31(4), 482-503. http://dx.doi.org/ 10.1521 /soco_2012_1005

Rullo, M., Livi, S., Pantaleo, G., \& Viola, R. (2017). When the black sheep is not so «black»: social comparison as a standard for ingroup evaluation in classrooms. Journal of Educational, Cultural and Psychological Studies (ECPS Journal), 1(15), 107-126.

Rullo, M., Presaghi, F., Livi, S., Mazzuca, S., \& Dessi, R. (2017). Time heals all (shallow) wounds: A lesson on forgiveness of ingroup transgressors learned by the Feyenoord Vandal fans. Social Sciences, 6(3), 83. http://dx.doi.org/10.3390/socsci6030083

Sammut, G., Bezzina, F., \& Sartawi, M. (2015). The spiral of conflict: Naïve realism and the black sheep effect in attributions of knowledge and ignorance. Peace and Conflict: Journal of Peace Psychology, 21(2), 289-294. http://dx.doi.org/10.1037/pac0000098

Schwartz, S. H. (2015). Basic individual values: Sources and consequences. In D. Sander, \& T. Brosch (Eds.), Handbook of value (pp. 63-84). Oxford, UK: Oxford University Press.

Tajfel, H., \& Turner, J. C. (1979). An integrative theory of intergroup conflict. The Social Psychology of Intergroup Relations, 33(47), 74.

Trevino, L. K., \& Victor, B. (1992). Peer reporting of unethical behavior: A social context perspective. Academy of Management Journal, 35(1), 38-64.

Waytz, A., Dungan, J., \& Young, L. (2013). The whistleblower's dilemma and the fairness-loyalty tradeoff. Journal of Experimental Social Psychology, 49(6), 1027-1033. http://dx.doi.org/10.1016/j.jesp.2013.07.002 